\title{
PORTUGAL, UMA SOCIEDADE DE CLASSES \\ Polarização social e vulnerabilidade \\ [Renato Miguel do Carmo (org.), 2012, Lisboa, Edições 70]
}

João Mineiro

Instituto Universitário de Lisboa (ISCTE-IUL), Lisboa, Portugal.

A questão das desigualdades sociais constituiu historicamente um objeto central da sociologia, não apenas na sua origem com os clássicos Marx, Webber ou Durkheim, mas também nas várias correntes que desde essa altura densificaram a sua abordagem teórica e as suas estratégias empíricas para pensar o fenómeno. Mesmo assumindo o caráter multidimensional das desigualdades, como têm defendido autores como Göran Therborn, Charles Tilly, Nancy Fraser ou até Pierre Bourdieu, o objeto específico das classes sociais continua a ser imprescindível no pensamento sobre as desigualdades.

Na sociologia portuguesa a discussão sobre as classes sociais aparece nos primórdios da afirmação da disciplina, com trabalhos de Adérito Sedas Nunes, João Ferreira de Almeida ou José Madureira Pinto. E foi, nos últimos 30 anos, objeto de consolidação e trabalho empírico muito robusto, de que são exemplos os trabalhos de António Firmino da Costa, João Ferreira de Almeida e Fernando Luís Machado, Elísio Estanque e José Manuel Mendes, Manuel Carlos Silva, José Luís Casanova, Virgílio Borges Ferreira e tantos outros autores que têm cruzado o campo das classes com outros campos da sociologia.

Portugal, Uma Sociedade de Classes, que Renato Miguel do Carmo organiza, convoca-nos para a continuação de um debate imprescindível e que se baseia num pressuposto absolutamente central, enfatizado no capítulo de abertura. É que durante muito tempo, principalmente a partir dos anos 90, o tema das classes sociais quase desapareceu do debate sociológico. Apesar do enorme arsenal teórico que Renato Miguel do Carmo procura mapear sobre este assunto, a partir dos anos 90 desenvolveu-se um campo intelectual que prematuramente anunciou, de forma mais ou menos direta, a perda de relevância das classes sociais como objetos particularmente importantes para pensar a sociedade contemporânea.

A pertinência deste livro começa nesse postulado: é que a crise financeira de 2008 e os processos sociais e económicos que temos vivido têm mostrado que as classes sociais não só não desapareceram, como se têm polarizado, e as desigualdades de classe continuam a ser absolutamente centrais na vida dos indivíduos.

Num livro recente embora anterior à crise, Paul Bouffartigue retomava o sociólogo Louis Chauvel para enunciar que estaríamos a assistir ao "regresso das classes sociais". Se é evidente que o regresso das classes ao debate não se fará, como o próprio Boltanski defende, recuperando as suas antigas formas de existência e representação, Portugal, Uma Sociedade de Classes vem retomar a complexidade deste debate, trabalhando-o empiricamente e enunciando que as desigualdades 
económicas e no trabalho, não sendo as únicas dimensões relevantes, são dimensões fundamentais para compreender o mundo em que vivemos.

É certo que a modernização e a terciarização da economia portuguesa, associada ao aumento da qualificação, à generalização dos serviços e à construção do modelo do estado-providência transformaram de forma determinante a sociedade portuguesa. Contudo, como Rosário Mauritti e Nuno Nunes advertem logo no segundo capítulo, a estrutura social portuguesa é ainda bastante carenciada de qualificações escolares e profissionais, o que é igualmente visível na distribuição das classes sociais em Portugal.

Diria que ao capítulo de Rosário Mauritti e Nuno Nunes, sobre a evolução da estrutura de classes na sociedade portuguesa, se podia propor uma nova interpelação: os percursos de continuidade e mudança na recomposição social portuguesa têm seguido uma tendência uniforme nestes últimos anos, ou a crise que desde 2008 se abateu sobre Portugal, a Europa e o mundo tem alterado a velocidade ou o sentido das recomposições sociais da sociedade portuguesa?

Estes últimos seis anos de crise financeira e económica tiveram como consequência também a inauguração de um novo ciclo de mobilizações sociais. Num capítulo importante sobre a relação entre as classes sociais e a cidadania política, Tiago Carvalho, em jeito de conclusão, argumenta seguinte:

os atuais protestos contra a política seguida não representam um aumento da confiança ou da participação política que aproximaria os cidadãos do Estado, pelo contrário o seu caráter pouco usual (sem continuidade através de outras ações e grupos) e a contestação das instituições e da "classe política" refletem uma distância à política. (pp. 77-78)

Não duvidamos, seguindo o argumento do autor, que a um posicionamento de classe desfavorecido corresponde tendencialmente um aumento do distanciamento em relação aos centros de decisão e de poder institucionais. Mas seria interessante explicar a outra dimensão do fenómeno. É que, à medida que estes novos movimentos sociais formulam uma crítica muito acérrima ao sistema político e económico (e às relações de promiscuidade entre estes), por outro lado, estes movimentos sabem encontrar em si mesmos formas de participação, de organização coletiva e de formulação de propostas e de alternativas.

Não me parece pois que se verifique um distanciamento em relação à política, mas sim um afastamento em relação à política institucional que é acompanhado por mecanismos de participação dentro dos movimentos e estratégias de disputa política, de que é exemplo paradigmático a Lei contra a Precariedade promovida pelo Movimento 12 de Março e os Precários Inflexíveis e que recolheu mais de 40 mil assinaturas e foi a discussão parlamentar.

De facto, como argumenta Vasco Ramos no terceiro capítulo, e que coloco aqui em discussão com os movimentos em torno da precariedade laboral, defender que existe hoje uma geração jovem com menos direitos e qualidade de vida que a geração mais velha esconde, por um lado, que quer na geração mais velha, quer na geração mais nova, existem indivíduos e grupos com condições de vida e de 
trabalho muito diversificadas, e esconde, por outro lado, que as situações de precariedade laboral e estabilidade na vida já afetam tanto as gerações mais jovens como as mais velhas. Contudo, parece-me que a autoidentificação de uma "geração à rasca" pode resultar de uma mudança profunda nas expetativas sobre as instituições. Esperava-se que o mercado, o estado e a economia proporcionassem condições de mobilidade social que permitissem aos jovens concretizarem as suas expetativas de vida e de trabalho. A verdade é que há hoje uma parte muito considerável da geração jovem que se confronta com um desemprego muito elevado, com níveis de precariedade crescentes e que viverá pior que a geração dos seus pais. Talvez por isso fosse interessante explorar a hipótese de que a mudança de expetativas sobre as instituições tem alimentado um sentimento de pertença geracional muito acentuado.

É impossível traçar um debate sobre as classes sociais desligado de uma perspetiva sobre o trabalho e as suas morfologias. Pensemos a título de exemplo que, quando refletimos sobre a generalização do emprego qualificado nos setores terciários com maiores salários, pensamos simultaneamente em processos de mobilidade social, ampliação das classes médias e mitigação da polarização social. Pelo contrário, à crise financeira, ao desemprego em massa, à redução salarial e ao processo de precarização do trabalho associamos uma acentuação da polarização social, uma diluição progressiva das classes médias e o reforço da estratificação de classe. Se é verdade que a crise financeira terá despoletado uma transformação acelerada da sociedade portuguesa neste segundo caminho, Portugal, apesar das evoluções, nunca deixou de ser um país profundamente desigual. Uma sociedade estruturalmente marcada por uma assimetria na distribuição de rendimentos que, como Margarida Carvalho refere no seu capítulo, se tem traduzido numa polarização cada vez maior entre as remunerações dos trabalhadores:

Em Portugal, o processo de modernização da sociedade e as grandes transformações sociais e culturais que ocorreram nas últimas décadas não se refletiram numa diminuição da estratificação ou das desigualdades sociais no mercado de trabalho. (p. 128)

Uma sociedade cuja distribuição assimétrica de rendimento se tem traduzido naquilo a que Frederico Cantante dá como título: uma considerável magreza das classes médias. Classes médias que, como o mesmo refere no capítulo 9, estão reféns do facto de Portugal apresentar níveis de concentração de rendimento familiar nos grupos de topo acima da média europeia e de uma acentuação nos últimos anos desta concentração. Falamos, para usar os termos de Margarida Carvalho no capítulo 8, de uma compressão dos grupos de ganho intermédio. Fenómenos complexos, numa sociedade que, como Pedro Abrantes demonstra, apesar de historicamente atrasada em relação à Europa, continua a lutar pela valorização dos seus trabalhadores à luz das suas experiências e conhecimentos de vida.

Identifica-se uma polarização social cujas consequências para o agravamento das desigualdades são notáveis, numa sociedade cuja desigualdade no trabalho tem profundas marcas societais, de que é exemplo paradigmático o caso de Mariana Bonfim, história de vida trazida a debate por Inês Brasão no capítulo 6 e que faz 
parte de um arrebatador estudo sobre a condição servil das trabalhadoras domésticas no século XX em Portugal ou a forma como a pertença ao trabalho transforma todas as esferas da vida dos indivíduos, incluido as suas discursificidades corporais, como demonstra de forma muito curiosa o capítulo 7 de Bruno Monteiro.

Por outro lado, novos desafios ao debate sociológico e ao futuro da política marcam a sociedade contemporânea. Seguimos a pista de Renato Miguel do Carmo no último capítulo e cuja conclusão do livro assume a forma de desafios para o futuro: num tempo de transformações aceleradas e de uma crise aprofundada em vários domínios da vida social, o processo de precarização do trabalho constitui um dos fenómenos mais importantes para pensar o trabalho, as classes sociais e as desigualdades. Em torno desse processo altamente complexo e estruturante correrá muita tinta, mas também muita incerteza, muitos dramas e muitas vidas. A haver sociologia, ela terá que percorrer também esses caminhos.

João Mineiro. Sociólogo, bolseiro de investigação científica na UNL e mestrando em sociologia no Instituto Universitário de Lisboa (ISCTE-IUL), Avenida das Forças Armadas, 1649-026, Lisboa, Portugal. E-mail: joao.mineiro.6@gmail.com 